\title{
AVALIAÇÃO MECÂNICA E ESTRUTURAL DA ADIÇÃO DE ESCORIA DO REFINO SECUNDÁRIO VIA ACIARIA ELÉTRICA EM MATERIAL CERÂMICO EM FUNÇÃO DO TEMPO DE ESTOCAGEM DO RESÍDUO
}

\section{MECHANICAL AND STRUCTURAL EVALUATION OF SECUNDARY REFINING SLAG ADDITION VIA ELECTRIC STEEL WORKS IN CERAMIC MATERIAL AS A FUNCTION OF WASTE STORAGE TIME}

\author{
MARÍLIA DUARTE CARDOSO, M.SC. | UNISINOS \\ ALINI LUÍSA DIEHL CAMACHO, M.SC. | UNISINOS \\ CARLOS ALBERTO MENDES MORAES, Dr. UUISINOS
}

\begin{abstract}
RESUMO
A caracterização e segregação são etapas que poderão indicar potencialidades de valorização e reaproveitamento de resíduos sólidos. Para a reciclagem de escória de refino secundário não há aplicações consolidadas, devido a sua alta densidade, assim como sua característica expansiva quando exposta ao ambiente em suas primeiras idades de estabilização, o que possibilita valorizá-la como coproduto minimizando resíduos em aterros e o impacto ambiental gerado. $\mathrm{O}$ objetivo deste estudo foi avaliar a reciclagem da escória de aciaria elétrica, em dois tempos de estocagem, 1 dia e 45 dias, através da sua incorporação em material cerâmico e verificar a influência do tempo de estocagem nas propriedades mecânicas e estruturais dos corpos cerâmicos produzidos. Foram produzidos, em laboratório, corpos de prova cerâmicos contendo escória do refino secundário de aciaria elétrica nos teores de adição de 5, 10 e 15 \% à argila. Os materiais foram previamente caracterizados e, nos traços estabelecidos, analisaram-se as propriedades de resistência mecânica na flexão, absorção de água e porosidade aparente. A retração linear em ambas as amostras foi maior após a secagem do que após a sinterização e, os resultados apresentaram queda na resistência mecânica nas adições de 10 e 15 \% de escória com 1 dia de estocagem, enquanto que em 45 dias de estocagem, as propriedades foram melhores, o que indica potencialidade de adição em material cerâmico nas condições avaliadas. Neste sentido, o tempo de estocagem deve ser ampliado para garantir a estabilização do resíduo, o que significa minimizar a presença de cal livre no coproduto que gera expansibilidade quando misturado com água durante os processos de secagem e sinterização do material cerâmico.
\end{abstract}

PALAVRAS CHAVE: Escória; Reciclagem; Aciaria Elétrica; Material Cerâmico.

\begin{abstract}
Characterization and segregation are steps that indicate the potential for recycling solid waste. For the recycling of secondary refining slag there are no consolidated applications, due to its high density, as well as its expansive characteristic when exposed to the environment in its early stabilizing ages, which makes it possible to value it as a co-product, minimizing waste in landfills and the environmental impact generated. In the laboratory, ceramic specimens containing slag from the secondary refining of an electric steel works were produced in the laboratory to assess their influence of storage time on mechanical and structural properties. The slags and the clay were previously characterized and, in the established lines, the properties of mechanical resistance in flexion, water absorption and apparent porosity were analyzed. The linear shrinkage in both samples was greater after drying than after sintering and the results showed a decrease in mechanical strength in the addition of 10 and $15 \%$ slag with 1 day of storage, whereas in 45 days of
\end{abstract}


storage, the properties were better, which indicates the potential for addition in ceramic material under the evaluated conditions. In this sense, the storage time must be extended to ensure the stabilization of the residue, which means minimizing the presence of free lime in the co-product that generates expandability when mixed with water during the drying and sintering processes of the ceramic material.

KEY WORDS: Slag; Recycling; Electric Steel works; Ceramic Material. 


\section{INTRODUÇÃO}

No Brasil, o processo siderúrgico gera em média, por tonelada de aço produzido, $450 \mathrm{~kg}$ de resíduos, subprodutos e coprodutos. Deste total e, dependendo da rota de produção tecnológica, $70 \%$ correspondem às escórias (ASSUNÇÃO, 2010; RONDA FILHO, 2016). Dos tipos de escórias gerados no processo industrial, um dos coprodutos de maior volume de geração, 30\% em média, é a escória de alto-forno (AFP) que contribui na faixa de 210 a 310 kg por tonelada de ferro gusa produzida (GEYER, 2001; ASSUNÇÃO, 2010; RONDA FILHO, 2016). No caso da escória de aciaria elétrica (FEA), a quantidade está na faixa de 100 a $150 \mathrm{~kg}$ por tonelada de aço produzido e, a geração de escória de forno panela está na ordem de 10 a $40 \mathrm{~kg}$ por tonelada de aço (ASSUNÇÃO, 2010). De acordo com o Instituto de Aço Brasileiro, em 2017 a geração de resíduos e coprodutos para cada tonelada de aço produzido foi em torno de $607 \mathrm{~kg}$, onde escória de alto-forno representou $42 \%$ e a escória de aciaria $27 \%$ do volume total gerado $(\mathrm{IABr}, 2018)$. É comum uma generalização das escórias, sejam elas AFP ou FEA, em muitos trabalhos científicos e tecnológicos, o que dificulta o estudo e a comparação dos resultados obtidos, apesar de terem composições químicas e comportamentos diferentes quanto a diversos fatores, como no caso da presença do óxido de cálcio livre (FISCHER e BARRON, 2019).

Nas siderúrgicas brasileiras, o processo de refino secundário via aciaria elétrica tipo forno panela é o mais utilizado em função do grande número de indústrias equipadas com estações de refino (RIZZO, 2006). Desta forma, tem aumentado a preocupação ambiental no que tange normas cada vez mais restritivas para ação humana exploradora dos recursos naturais, tendo em vista, que o aço possui uma grande afinidade com a proteção ambiental por ser imediatamente reciclável, quando comparado a outros metais (ASSUNÇÃO, 2010).

No refino secundário, o óxido de cálcio $(\mathrm{CaO})$ é adicionado como agente fundente e fluxante, tendo como principal função, escorificar as impurezas e diminuir a temperatura de fusão da carga (MORAES et al, 2009). A quantidade aproximada consumida no FEA na produção de aços comuns é de 25 a $30 \mathrm{~kg}$ de cal calcítica e de 7 a 12 $\mathrm{kg}$ de cal dolomítica por tonelada de aço líquido (MORAES et al, 2009; CARDOSO, 2009).

Uma das grandes limitações em relação à utilização da escória como coproduto é o seu fator de expansibilidade que ocorre devido à presença de $\mathrm{CaO}$ livre e óxido de magnésio $(\mathrm{MgO})$ reativo, além de óxidos de ferro e silicatos de cálcio que provocam fissuras, seguidas de desintegração
(CESAR, 2008; GRAFFITTI et al, 2005; CIKMIT et al, 2019; VIEIRA et al, 2013). Segundo Cesar (2008), recomenda-se um prévio estudo do comportamento da escória antes de sua utilização, pois a causa da expansão é devido à presença de sais solúveis que, quando hidratados, aumentam de volume. Fisher e Barron (2019) reforçam que o reaproveitamento das escórias siderúrgicas é, muitas vezes, limitado. Muitas aplicações potenciais são descartadas quando a umidade presente nas escórias pode facilmente causar expansão devido à instabilidade no volume. Por serem estocadas ao ar livre, as escórias tornando-se vulneráveis a curto e longo prazo devido à hidratação dos óxidos de Ca e Mg. Outro fator que também influencia na expansão da escória é a corrosão do ferro metálico $(\mathrm{FeO})$ e mudanças nas formas alotrópicas do $2 \mathrm{CaO}$. SiO2 (CIKMIT et al, 2019; COSTA et al, 2017). Alguns estudos indicam um período de estocagem da escória, pois o resíduo deve ficar a um longo período estocado para passar por um processo de cura onde os óxidos livres estejam hidratados e a expansão estabilizada (COSTA et al, 2017; SORLINI et al, 2012). Nos últimos anos, dois métodos foram desenvolvidos para estabilizar a cal livre na escória e impedir a expansão do volume: oxidação ao ar e redução carbotérmica (FISCHER e BARRON, 2019). Desta forma, a escória estável pode substituir recursos naturais, como, por exemplo, o calcário agregado em construções envolvendo concreto (CIKMIT et al, 2019).

As aplicações da FEA têm mostrado potencialidades como coproduto na forma de matéria-prima na construção civil, em pavimentação de estradas (MARCACCINI, 2009; SILVA, 2013), construção de gabiões, misturas asfálticas, como base e sub-base de rodovias, fertilizantes, contenção em margens de rios, diques marítimos, etc (CESAR, 2008; RÊGO, 2010). Outras pesquisas utilizaram a escória como adição ou substituição parcial na composição de materiais, sendo que algumas indicam que ela pode ser reciclada através de sua associação com outros resíduos (COLLATTO, 2008; CARDOSO, 2009; RÊGO, 2010). Segundo Rêgo (2010), muitas pesquisas estão incorporando resíduos em massas cerâmicas com o intuito de reduzir impactos ambientais causados por eles, bem como melhorar propriedades funcionais e estruturais nas cerâmicas vermelhas. Do ponto de vista ambiental, pesquisas mais promissoras estão relacionadas aos processos de vitrocerâmica, cerâmica estrutural, esmalte cerâmico e processos de vitrificação (STATHOPOULO et al, 2013; WANNAKAMB et al, 2013; HU et al, 2011). No entanto, aspectos relacionados às propriedades físicas, composição química e conteúdo mineral na escória apresentam desafios a serem superados para a viabilidade técnica e comercial de novas e antigas propostas de destino (BUZIN et al, 2017). 
Desta forma, a indústria cerâmica brasileira é considerada importante não só pela questão social através da geração de empregos, mas também por uma forte ligação com a construção civil que demanda maior atenção pela extração de recursos naturais e, nos últimos anos tem atraído os holofotes para a reciclagem de resíduos industriais (BUZIN et al, 2017; VIANA et al, 2010). Cabe salientar que a maioria das unidades produtoras de cerâmica estrutural segmentada na construção civil é composta por pequenas empresas familiares e que possui um papel importante na sociedade. Estima-se que essas empresas são responsáveis por 293 mil empregos diretos espalhados por todo o país, segundo dados da ANICER - Associação Nacional da Indústria Cerâmica (ANICER, 2017; DO PADRO e BRESSIANI, 2013).

Adições de $15 \%$ de escória de aciaria em material cerâmico apresentaram resultados com melhorias consideráveis nas propriedades físicas e mecânicas com temperatura abaixo de $850^{\circ} \mathrm{C}$ para queima (REGO, 2010). Castro et al (2016) verificaram a potencialidade de uso dos resíduos siderúrgicos em blocos intertravados de solo-cimento para alvenaria sustentável com bons resultados em até $20 \%$ em massa de escória granulada de forno elétrico a arco. Peças cerâmicas preparadas por prensagem uniaxial e queimadas entre 850 e $950^{\circ} \mathrm{C}$ comprovaram o uso do resíduo de escória na incorporação em cerâmica vermeIha como substituto parcial da argila natural (VIEIRA et al, 2013; VIANA et al, 2010). Segundo Vieira et al (2013), o estágio de combustão na faixa de temperatura entre 600 e $1000^{\circ} \mathrm{C}$ é um fator fundamental para a consolidação de partículas, pois permite a volatilização de compostos perigosos e a inertização de compostos potencialmente tóxicos, através da fixação na fase vítrea. A utilização de alguns tipos de resíduos contribui para facilitar a fabricação de cerâmica vermelha, pois altera a plasticidade e/ou trabalhabilidade do corpo cerâmico e, também, melhora o desempenho técnico da cerâmica associado a um aumento da resistência mecânica e diminuição de absorção de água (RÊGO, 2010; BUZIN et al, 2017).

O presente trabalho teve como objetivo avaliar a reciclagem da escória de forno panela de aciaria elétrica (FEA) gerada durante o refino secundário no processo siderúrgico de fabricação do aço através de sua incorporação em material cerâmico. Baseado nas etapas prévias de caracterização e segregação do resíduo teve a finalidade de verificar a influência do tempo de estocagem nas propriedades mecânicas e estruturais dos corpos de prova cerâmicos.

\section{MATERIAIS E MÉTODOS}

A FEA utilizada neste trabalho é oriunda do processo secundário via aciaria elétrica de uma empresa do setor siderúrgico. A argila utilizada no programa experimental foi doada pela Olaria Brasil, proveniente de uma jazida localizada na região metropolitana de Porto Alegre, RS. A metodologia desenvolvida compreendeu cinco etapas: 1- amostragem da escória; 2- segregação da escória; 3caracterização físico-química nas escórias e argila; 4- formulação, conformação, secagem, confecção dos corpos de prova (CP) e sinterização; e por fim, 5- avaliação das propriedades mecânicas. A Figura 1 representa detalhadamente as etapas realizadas.

\subsection{Amostragem das escórias e segregação}

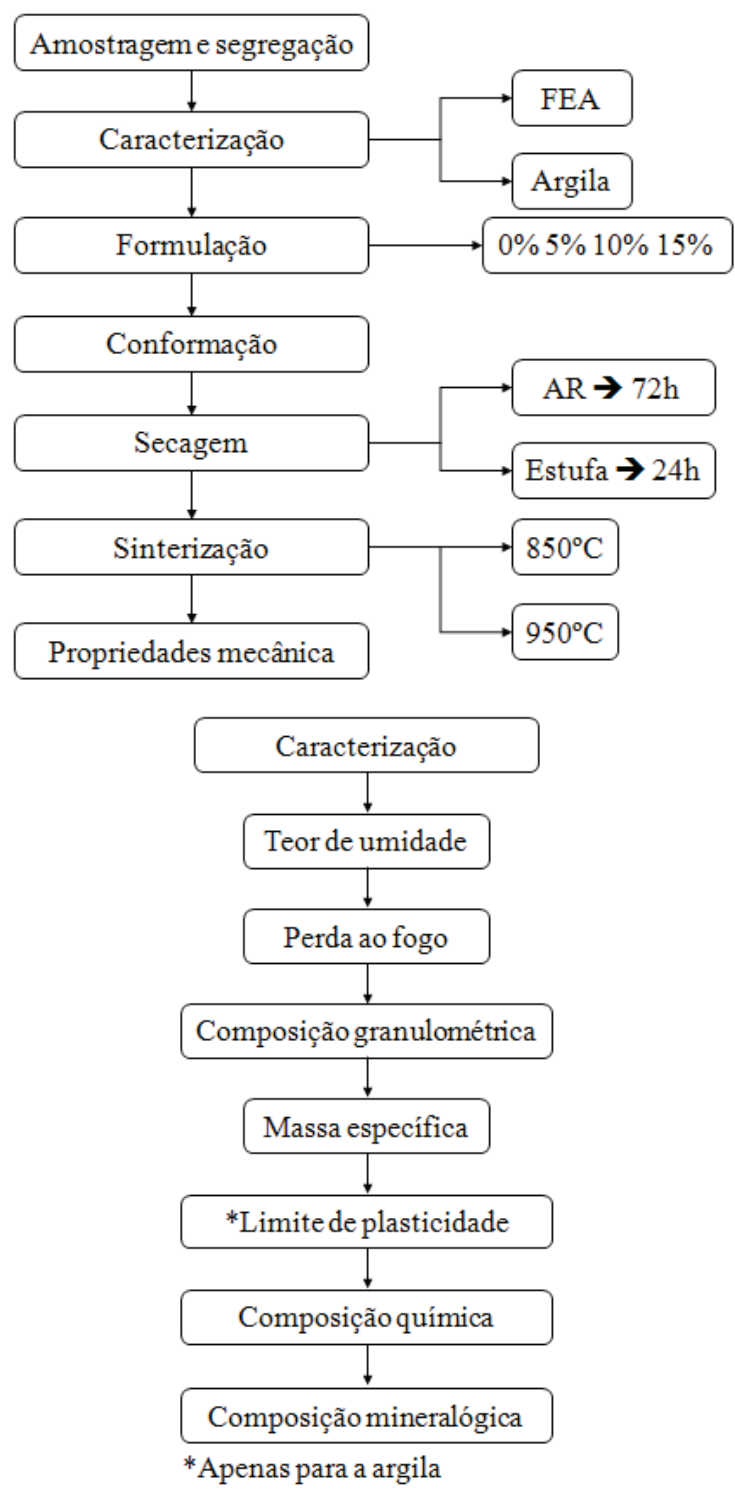

Figura 01 - Etapas detalhadas da metodologia e caracterização empregada Fonte: Adaptado de Cardoso (2009) 
Os resíduos de escória foram amostrados conforme a NBR 10.007 (ABNT, 2004). Durante a amostragem foram coletadas escórias de duas pilhas no próprio local de disposição na aciaria, em tempos de estocagem correspondentes a 1 dia (D1) e 45 dias (D45). Cerca de 50 kg de cada pilha foram acondicionados em tonéis, e consequentemente, um segundo estágio de quarteamento resultou em 6 kg de material para cada pilha.

\subsection{Caracterização dos materiais}

Para a caracterização dos materiais (FEA e argila) foram empregadas as técnicas apresentadas na Tabela 1 e, suas respectivas normas estão indicadas. Para a determinação da composição química da argila de forma qualitativa foi utilizada a técnica de fluorescência de raios $X$ (FRX) pelo equipamento marca Shimadzu, modelo EDS-720. Para as amostras de FEA, a análise de composição química foi determinada quantitativamente no laboratório da empresa siderúrgica pelo equipamento marca Rigaku, modelo RIX 3100.

\begin{tabular}{|l|l|}
\hline Técnicas adotadas & Normas \\
\hline Teor de umidade & CEMP 105:2003 \\
\hline Perda ao fogo & CEMP 120:2003 \\
\hline Composição granulométrica & NBR NM 248:2001 \\
\hline Massa específica & NBR 6508:1984 \\
\hline Limite de plasticidade & NBR 7180:2016 \\
\hline
\end{tabular}

Tabela 01: Técnicas empregadas na caracterização dos materiais Fonte: autores (2020)

Para a identificação das fases mineralógicas nas amostras de FEA foi empregada à técnica de difração de raios $X$ (DRX) através do equipamento difratômetro marca Siemens, modelo D5000 e sua identificação no software Philips X' Pert Graphics \& Identify. Os métodos de análises térmicas utilizados foram a termogravimetria e análise térmica diferencial pelo equipamento marca BP Engenharia, modelo $R B^{*} 3000 * 20$.

2.3. Formulação, conformação, secagem, confecção dos corpos de prova e sinterização

Foram confeccionados 700 corpos de prova (CP) cerâmicos, sendo $100 \mathrm{CP}$ para o corpo de prova referência e $600 \mathrm{CP}$ com as adições de FEA para as amostragens de D1 e D45. Para o desenvolvimento da formulação correspondente a relação argila x FEA x água foi tomado como base a adição mínima de água, pois segundo Kazmiercsak (2007), teores excessivos podem gerar elevadas contrações durante as etapas de secagem e sinterização, gerar aumento na porosidade, perda de resistência mecânica e aumentar a permeabilidade à água. Os teores de FEA adicionados à argila utilizados para os traços D1 e D45 estão apresentados conforme segue na Tabela 2.

\begin{tabular}{|c|c|c|c|}
\hline & & \multicolumn{2}{|l|}{ Traços } \\
\hline & & D1 & D45 \\
\hline \multirow{3}{*}{ 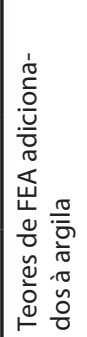 } & $5 \%$ & $\begin{array}{l}\text { Argila } 12 \mathrm{~kg} \\
\text { Escória } 1,2 \mathrm{~kg} \\
\text { Água } 27,62 \%\end{array}$ & $\begin{array}{l}\text { Argila } 12 \mathrm{~kg} \\
\text { Escória 1,2 kg } \\
\text { Água } 27,77 \%\end{array}$ \\
\hline & $10 \%$ & $\begin{array}{l}\text { Argila } 12 \mathrm{~kg} \\
\text { Escória } 2,4 \mathrm{~kg} \\
\text { Água } 26,25 \%\end{array}$ & $\begin{array}{l}\text { Argila } 12 \mathrm{~kg} \\
\text { Escória } 2,4 \mathrm{~kg} \\
\text { Água } 26,21 \%\end{array}$ \\
\hline & $15 \%$ & $\begin{array}{l}\text { Argila } 12 \mathrm{~kg} \\
\text { Escória } 3,6 \mathrm{~kg} \\
\text { Água } 25,58 \%\end{array}$ & $\begin{array}{l}\text { Argila } 12 \mathrm{~kg} \\
\text { Escória } 3,6 \mathrm{~kg} \\
\text { Água } 25,64 \%\end{array}$ \\
\hline
\end{tabular}

Tabela 02: Formulações utilizadas

Fonte: Adaptado de Cardoso (2009)

Os CP verdes foram extrusados em uma maromba a vácuo, marca Verdés, modelo 051, em formatos retangulares, medindo valores médios de 19,39 x $81 \mathrm{~mm}$ e espessura de $10,25 \mathrm{~mm}$. A secagem ao ar foi realizada pela exposição dos CP em sala climatizada com temperatura constante de $24 \pm 1^{\circ} \mathrm{C}$ e umidade relativa de $70 \%$. O tempo de secagem foi de $72 \mathrm{~h}$, visualmente suficiente para o desaparecimento da umidade superficial dos CP e nas primeiras $24 \mathrm{~h}$ foram cobertos com pano úmido. A secagem em estufa foi realizada com temperatura de $100^{\circ} \mathrm{C}$ por $24 \mathrm{~h}$. De acordo com Collatto (2008), os CP após serem conformados, geralmente possuem 5 a $35 \%$ de umidade que deve ser removida, pois a água retida em seu interior pode gerar tensões internas e fendilhamento, o que exige esta etapa de secagem.

Após a secagem, os CP foram avaliados quanto à análise visual (observados através de lupa petrográfica, marca Leica Microsystems, modelo MS 5, com câmera para captura de imagem JVC TK C720U), perda ao fogo, resistência mecânica (flexão a 3 pontos), segundo a NBR 15270-1 (ABNT, 2005), retração linear na secagem, perda de massa, análise térmica diferencial e termogravimétrica.

As temperaturas de sinterização foram estabelecidas em $850^{\circ} \mathrm{C}$ e $950^{\circ} \mathrm{C}$, justamente para simular as mesmas temperaturas utilizadas na prática em Olarias. A sinterização ocorreu em forno elétrico, modelo DTT1250, marca Sanchis. Os CP, após sinterização, foram avaliados quanto a retração linear na queima (30 P), resistência mecânica à compressão na flexão a 4 pontos, segundo a NBR 15270-1 (ABNT, 2005) em equipamento universal de ensaio, modelo DL 2000, Classe I, marca EMIC, bem como, avaliou-se a absorção de água e porosidade aparente (20 CP e analisados pelo princípio de Arquimedes). 
O tratamento dos dados foi realizado em software Excel através da estatística descritiva dos valores de amplitude de movimento considerando a média e desvio padrão dos resultados obtidos. A análise dos resultados foi realizada através dos gráficos gerados a partir da média dos corpos de prova (variável para cada ensaio) e desvio padrão máximo e mínimo, o que resultou em uma barra de erros.

\section{RESULTADOS E DISCUSSÕES}

\subsection{Amostragem e segregação das escórias}

A caracterização das escórias possibilitou a visualização de uma grande heterogeneidade, composta por refratários, arames, plásticos, lã de vidro, concreto, materiais cerâmicos, de acordo com a Figura 2.

Após a realização da segregação, foi possível subdividir o material em escória graúda e escória miúda. A segregação mostrou-se ser uma etapa fundamental para a caracterização e viabilização do programa experimental, onde a escória de forno panela foi adicionada à argila, para a produção de cerâmica vermelha. A fração de escória adicionada ao material cerâmico foi correspondente a granulometria $\leq$ peneira 30 \# $(0,59 \mathrm{~mm})$, material segregado referente à letra (d) da Figura 2.

Segundo Vieira et al (2013), o tamanho de partículas da escória deve estar abaixo de $2 \mathrm{~mm}$ para o processamento de cerâmica vermelha. Além disso, uma das considerações é que ao se avaliar a possibilidade de transformar o resíduo escória em coproduto, a empresa deve implementar uma gestão que garanta a não contaminação do mesmo com outros materiais que inviabilizariam sua adição ao processo de produção industrial de cerâmica vermelha.
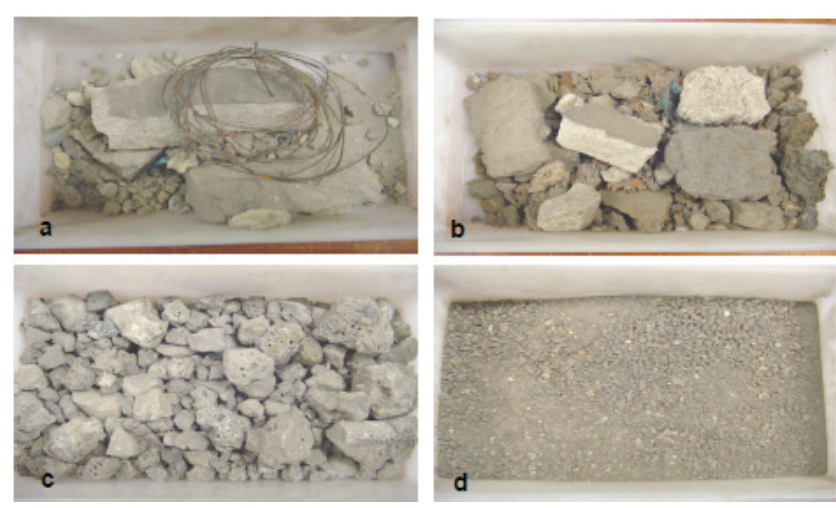

Figura 2 - (a) refratário, arame, plástico, lã de vidro; (b) concreto, materiais cerâmicos, papel material segregado; (c) escória graúda; (d) escória miúda

Fonte: Cardoso (2009)

\subsection{Ensaios de caracterização nos materiais}

A análise de FRX mostrou que na escória D1 os elementos atingiram 68,95 \% do total da composição química e na escória D45 correspondeu a 50,47 \%, sendo o restante, essencialmente o elemento oxigênio. As principais diferenças encontradas entre os elementos das amostras D1 e D45 foram o ferro (Fe) com 13,11 e 19,20 \%, o alumínio (Al) com 6,28 e 4,16 \% e o cálcio (Ca) com 21,35 e 19,32 \%. Os demais elementos podem ser visualizados na Tabela 3.

\begin{tabular}{|l|l|l|l|l|l|l|l|l|l|l|l|l|l|}
\hline Elementos (\%) & $\mathbf{S i}$ & $\mathbf{C a}$ & $\mathbf{F e}$ & $\mathbf{M g}$ & $\mathbf{A l}$ & $\mathbf{M n}$ & $\mathbf{C r}$ & $\mathbf{P}$ & $\mathbf{S}$ & $\mathbf{T i}$ & $\mathbf{N a}$ & $\mathbf{K}$ & $\mathbf{V}$ \\
\hline $\mathrm{D} 1$ & 14,9 & 21,35 & 13,11 & 9,56 & 6,28 & 1,7 & 0,95 & 0,07 & 0,29 & 0,19 & 0,3 & 0,2 & 0,054 \\
\hline D45 & 13,85 & 19,4 & 19,2 & 10,01 & 4,16 & 1,7 & 0,59 & 0,09 & 0,37 & 0,17 & 0,11 & 0,08 & 0,05 \\
\hline
\end{tabular}

Tabela 03: Composição química elementar das escórias D1 e D45 Fonte: Adaptado de Cardoso (2009)

A composição química qualitativa da argila apresentou os elementos Si e Fe como majoritários, $\mathrm{Al}, \mathrm{K}, \mathrm{Ca}, \mathrm{Ti}$ e $\mathrm{Mn}$ como elementos minoritários e $\mathrm{Mg}, \mathrm{Rb}, \mathrm{Sr}, \mathrm{P}$ e $\mathrm{Zr}$ como elementos traços. A presença do elemento $\mathrm{Ca}$, em valores menores na amostra D45 do que na amostra D1, pode ser caracterizada por uma possível lixiviação deste elemento na forma de óxido de cálcio hidratado. Graffitti (2002) encontrou, em função da lixiviação do $\mathrm{Ca}, \mathrm{CaO}$ hidratado em condições semelhantes pela formação de tufa. Durante a amostragem, observou-se regiões brancas na base da pilha, possivelmente devido à presença de sais e hidróxidos solúveis, característicos de Ca e Mg (CESAR, 2008; COSTA et al, 2017; DOS SANTOS e
QUEIROZ, 2016). A presença do Fe de forma majoritária na amostra D45 é explicada devido a um beneficiamento menos eficiente nesta escória.

De acordo com Khattab et al (2017), a composição química pode variar significativamente de uma unidade de produção do aço para outra, uma vez que está relacionada à qualidade da matéria-prima, ao tipo de aço produzido, aos materiais e aos parâmetros de processamento do refino do aço. As concentrações dos elementos podem sofrer alterações devido a variações na qualidade e quantidade de sucata adicionada no forno de arco elétrico (BUZIN et al, 2017). Pickles (2008) cita a presença do elemento Ca como o terceiro elemento metálico em maiores quantidades 
presente no resíduo, valores semelhantes a este estudo. Quanto maior a quantidade de Ca, maior será a basicidade da escória. À medida que o teor de Ca aumenta, as propriedades cimentícias da escória também aumentam (REHÁCKOVÁ et al, 2015). Os difratogramas das escórias D1 e D45 estão apresentados na Figura 3. Compostos expansivos (óxidos de cálcio e magnésio) conforme verificado por Zettermann (2001) e Graffitti (2002) indicam que os picos cristalinos geralmente ocorrem sobrepostos em escórias de aço inoxidável e, devido a sua complexa composição química, outras fases cristalinas minoritárias também podem existir (VIEIRA et al, 2013). Em especial, na amostra D1 a presença do Fe foi observada em quatro outras formas de estrutura cristalina, tais como a wustita, magnetita, mangesioferrita e óxido de ferro. Na amostra D45 os compostos identificados foram óxido de cálcio e magnésio livres, periclásio, gelenita, espinélio e óxido de ferro. Compostos de silicato de cálcio e magnésio foram encontrados na literatura em proporções mais baixas, através de uma análise semi-quantitativa, nas formas cristalinas de calcita e quartzo, em que o componente amorfo/vítreo está em uma proporção intermediária (10 a $20 \%$ em peso), indicado pela presença de um pequeno alo de amorfismo em ângulo $2 \theta$ (5 a $20^{\circ}$ ), característica também presente nas amostras D1 e D45 (GALÁN-ARBOLEDAS et al, 2017).
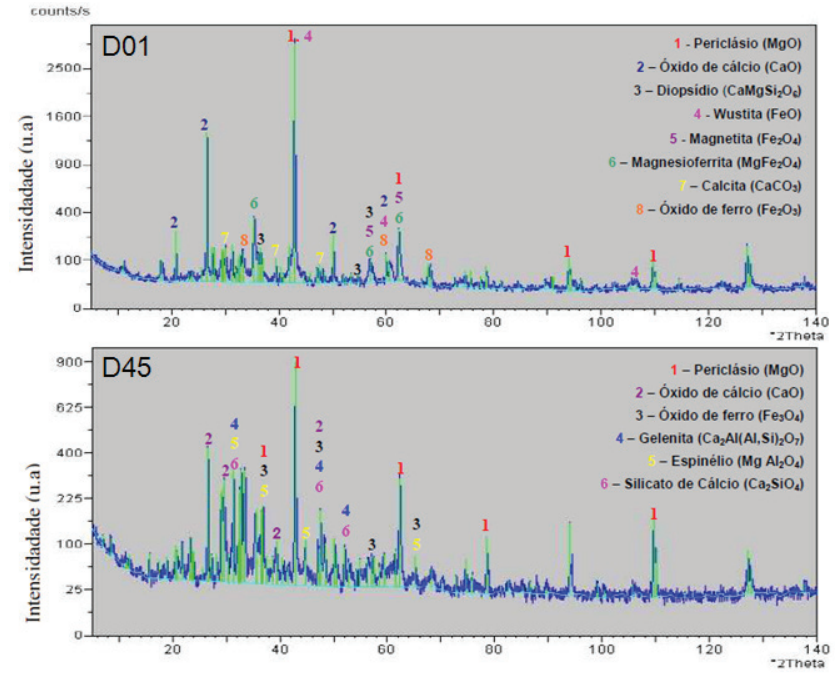

Figura 3 - Difratogramas das escórias D1 e D45 Fonte: Cardoso (2009)

Para os resultados correspondentes às análises termogravimétricas, a Tabela 4 é apresentada. A perda de massa total foi maior na escória D1, provavelmente devido a esta ter sido beneficiada mais recentemente. Em ambas as amostras, ocorreram perdas de massa correspondentes a reações endotérmicas entre as temperaturas de 95 e $210^{\circ} \mathrm{C}$, atribuídas à perda de água (GALÁN-ARBOLEDAS et al, 2017). Entretanto, uma reação exotérmica, característica de descarbonatação, citada por Gumieri (2002) e Graffitti (2002), ocorreu em $865^{\circ} \mathrm{C}$.

\begin{tabular}{|l|l|l|l|}
\hline Escórias & Temp. & $\begin{array}{l}\text { Perda de } \\
\text { massa }\end{array}$ & $\begin{array}{l}\text { Perda de } \\
\text { massa total }\end{array}$ \\
\hline \multirow{2}{*}{ D1 } & $153^{\circ} \mathrm{C}$ & $3,64 \%$ & $8,55 \%$ \\
\cline { 2 - 3 } & $786^{\circ} \mathrm{C}$ & $3,90 \%$ & \\
\hline \multirow{2}{*}{ D45 } & $139^{\circ} \mathrm{C}$ & $4,56 \%$ & $6,04 \%$ \\
\cline { 2 - 3 } & $709^{\circ} \mathrm{C}$ & $1,56 \%$ & \\
\hline
\end{tabular}

Tabela 04: Perdas de massa nas escórias D1 e D45 Fonte: Adaptado de Cardoso (2009)

O mesmo fenômeno ocorreu para Galán-Arboledas et al (2017), porém em adições de 10, 20 e 30 \% de escória à argila. O CaO livre é proveniente da decomposição anterior de carbonatos (calcita + dolomita), avaliados até a temperatura final do teste de $1050^{\circ} \mathrm{C} \mathrm{e}$, uma vez terminada essa decomposição, ocorre um ganho de massa muito pequeno nas misturas devido à oxidação de alguns compostos presentes na escória. Este fato não foi observado neste estudo, uma vez que, as amostras foram submetidas até temperatura de $1000^{\circ} \mathrm{C}$.

A massa específica das escórias pode variar muito em função do tipo de processo de geração. Para as escórias estudadas, D1 e D45, os valores encontrados foram de 2,82 e $3,05 \mathrm{~g} / \mathrm{cm}^{3}$, conforme Tabela 5, valores próximos encontrados na literatura (COSTA et al, 2017; VIANA et al, 2010).

O fato da amostra D45 ter apresentado uma massa específica um pouco maior em relação a D1 se deve, principalmente, a maior quantidade de ferro encontrada em sua composição. A perda ao fogo da escória D45 foi bem menor em relação à escória D1 e, isto se deve ao fato provável relacionado ao tempo de estocagem do material, o que pode estar relacionado a um aumento na sua estabilização química. O limite de plasticidade da argila encontrado foi de $28,73 \%$. Segundo Viana et al (2010), à medida que se adiciona o resíduo de escória à argila, a tendência é reduzir a plasticidade da cerâmica vermelha. Cikmit et al (2019) salientam que quanto maior o teor de escória adicionada, mais difícil é a mistura, uma vez que a escória pode absorver grande parte da água livre presente na argila. Valores semelhantes de massa específica foram encontrados na literatura, para a argila em $2,70 \mathrm{~g} / \mathrm{cm}^{3}$ e, para a escória em $3,17 \mathrm{~g} / \mathrm{cm}^{3}$, mesmo tratando-se de materiais de origens diferentes (GALÁN-ARBOLEDAS et al, 2017).

\subsection{Ensaios após etapa de secagem}

Nessa etapa os CP passaram pelos ensaios de retração linear e resistência mecânica na flexão. No ensaio de retração linear na secagem foram analisadas 50 medidas de CP para cada 
teor de adição e seu comportamento está apresentado na Figura 4. Para o traço D1, a variação de retração linear na secagem ficou na faixa de 4,9 a 6,93 \%, enquanto no traço D45, ficou entre 4,41 e 7,26 \%. De uma forma geral, um aumento da proporção da adição de escória na mistura diminuiu a resistência mecânica na flexão, corroborando com resultados apresentados por Galán-Arboledas et al (2017), em adições de escória de 10, 20 e 30 \%. Este declínio está relacionado à menor plasticidade das composições contendo escória.
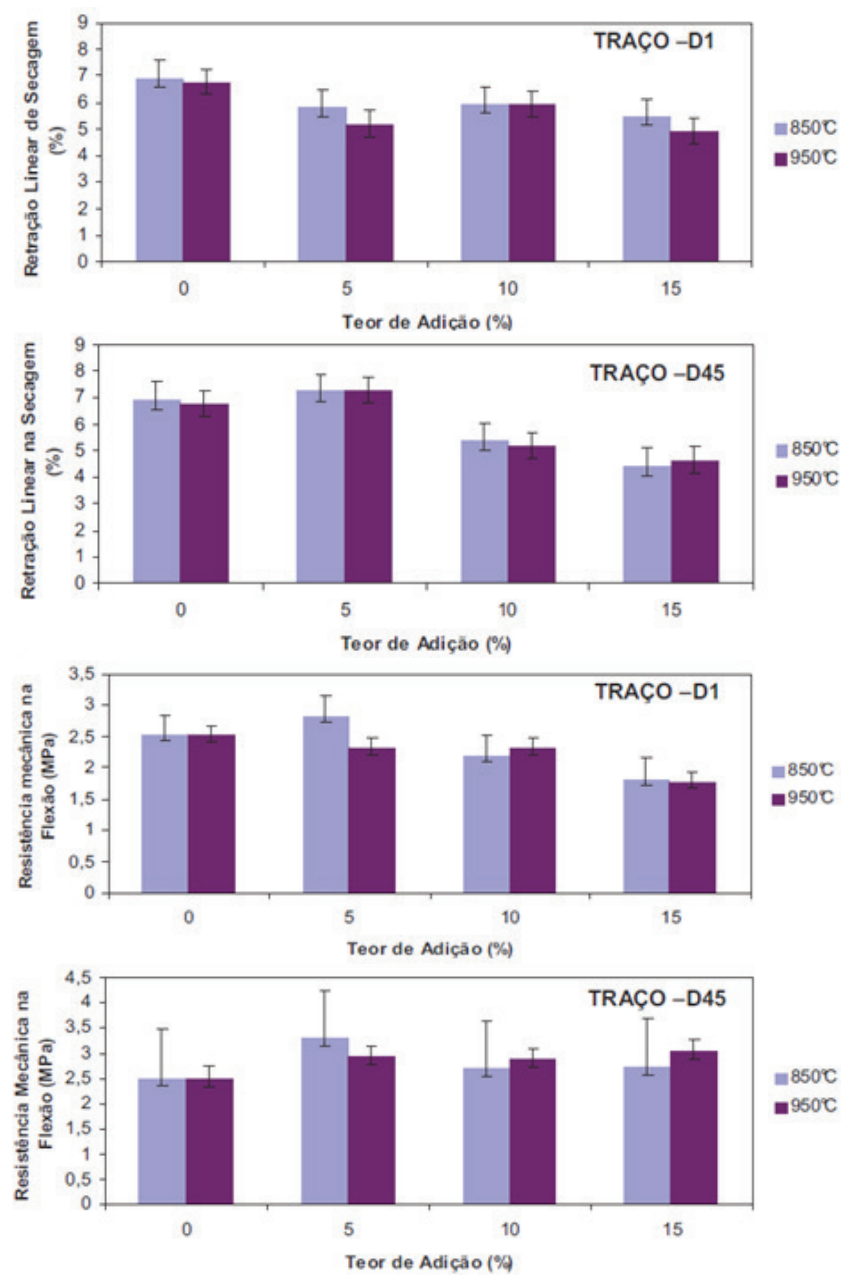

Figura 04 - Retração linear na secagem e resistência mecânica na flexão Fonte: Cardoso (2009)

Para o ensaio de resistência mecânica à flexão foram analisadas 10 medidas de CP, cujos resultados estão representados na Figura 4. Como a tensão de ruptura mínima na secagem para a massa cerâmica deve ser de 2,5 MPa, os CP do traço D1 apresentaram uma resistência mecânica menor à medida que o teor de escória foi aumentado, exceto no teor de $5 \%$ de escória no material cerâmico sinterizado na temperatura de $850^{\circ} \mathrm{C}$. Entretanto, os CP do traço D45 apresentaram resultados superiores à referência para ambas as adições de escória, nas temperaturas estudadas de 850 e $950{ }^{\circ} \mathrm{C}$. Em relação à referência, o traço D1 com 5 \% de escória apresentou resistência mecânica maior. Nos traços D45, os CP sinterizados a $850^{\circ} \mathrm{C}$, com 10 e $15 \%$ de adição de escória, apresentaram valores de resistência mecânica acima da referência, enquanto na temperatura de $950^{\circ} \mathrm{C}$, nenhum $\mathrm{CP}$ apresentou resistência mecânica na flexão superior à referência.

De fato, a resistência mecânica na flexão deveria aumentar quando o teor de argila aumentasse nas misturas estudadas, porém, isto não foi observado, pois o processo de moldagem é altamente dependente do tamanho das partículas e, a plasticidade é a propriedade característica dos minerais argilosos, os filossilicatos, especialmente as esmectitas, de grãos finos ( $<2$ um) responsáveis pelo aumento da fração de partículas finas na argila. Além disso, o tamanho de partículas da escória também pode influenciar nesta propriedade, pois ter uma distribuição de tamanho de partícula diferente da argila pode causar um empacotamento de partículas diferente durante a formação, o que reduz a resistência mecânica (GALÁN-ARBOLEDAS et al, 2017).

\subsection{Ensaios após a sinterização}

Os CP após a etapa de sinterização passaram pelos ensaios de análise visual via lupa, perda ao fogo, retração linear na queima (30 medidas), resistência à compressão na flexão a 4 pontos (20 medidas), absorção de água e porosidade aparente (20 medidas).

Na análise visual por lupa, ambos os traços apresentaram pontuações brancas e escuras em sua superfície, caracterizadas diretamente ao teor de adição de escória e à temperatura de sinterização. Verificou-se, conforme a Figura 5, que as pontuações brancas presentes estão provavelmente relacionadas ao CaO livre, enquanto as pontuações escuras (Figura 6), segundo Nishigaki (2000) relacionadas a óxidos metálicos oriundos da escória. Além disso, nos CP sinterizados a 950 ${ }^{\circ} \mathrm{C}$, a presença do $\mathrm{CaO}$ livre é mais acentuada do que nos $\mathrm{CP}$ sinterizados a $850^{\circ} \mathrm{C}$, o que corrobora com as análises de difração de raios $X$ realizadas nas escórias isoladamente, as quais apresentaram estes compostos cristalinos em suas estruturas (DOS SANTOS e QUEIROZ, 2016).

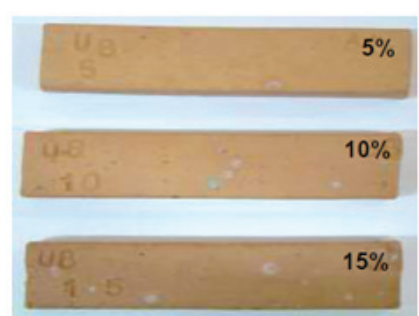

(a)

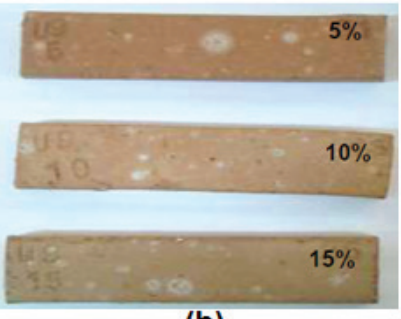

(b)
Figura 05 - Corpos de prova sinterizados a $850^{\circ} \mathrm{C}$ (a) e sinterizados a $950^{\circ} \mathrm{C}(\mathrm{b})$ Fonte: Adaptado de Cardoso (2009) 


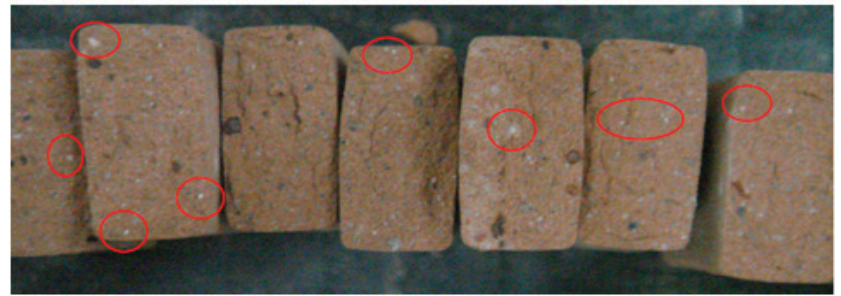

Figura 06 - Partículas metálicas presentes nos corpos de prova pela presença de pontuações escuras Fonte: Cardoso (2009)

O mecanismo de expansão e que, de fato causa estas pontuações brancas na superfície dos CP, é causado, segundo Cikmit et al (2019), pelo aumento da fase sólida na situação hidratada. A cal livre, originalmente, possui uma massa específica de $3,34 \mathrm{~g} / \mathrm{cm}^{3}$ e, quando reage com a água, produz portlandita $[\mathrm{Ca}(\mathrm{OH}) 2]$ que muda a massa específica para $2,23 \mathrm{~g} / \mathrm{cm}^{3}$, ela empurra outras fases sólidas, o que resulta em um aumento de volume.

Os resultados de perda ao fogo, conforme Tabela 6, dos traços D1 e D45 foram maiores em relação à referência, com exceção do traço D45 com 10 e 15 \% de adição de escória. Os valores encontrados coincidem com os valores apresentados para as escórias analisadas isoladamente.

\begin{tabular}{|l|l|}
\hline Traços & Perda ao fogo \\
\hline Referência & $4,14 \%$ \\
\hline D1 com $5 \%$ & $4,38 \%$ \\
\hline D1 com 10 \% & $4,25 \%$ \\
\hline D1 com 15 \% & $4,28 \%$ \\
\hline D45 com 5\% & $4,30 \%$ \\
\hline D45 com 10\% & $4,08 \%$ \\
\hline D45 com 15 \% & $3,84 \%$ \\
\hline
\end{tabular}

Tabela 06: Perda ao fogo dos corpos cerâmicos Fonte: Cardoso (2009)

Segundo Paschoal (2003), a retração linear de queima aceitável na sinterização é de até $8 \%$. Para este ensaio, foram analisados 30 CP. Conforme a Figura 7, a variação de retração linear após a sinterização para o traço D1 ficou entre 0,21 a 2,93 \%, enquanto que no traço D45, entre 0,21 e $2,83 \%$, sendo que para ambos os traços a retração linear aumentou para os CP sinterizados a $850^{\circ} \mathrm{C}$. Valores foram encontrados compreendidos na faixa apropriada para fabricação de produtos de cerâmica vermelha para a construção civil (ABNT, 2005; PASCHOAL, 2003). Este mesmo comportamento não foi encontrado para os $\mathrm{CP}$ sinterizados na temperatura de $950{ }^{\circ} \mathrm{C}$, onde nestes, ocorreu um aumento da retração linear com o aumento do teor de adição de escória no traço D1 com adições de 10 e 15 \%. Entretanto, para o Traço D45, o mesmo efeito foi verificado no teor de $15 \%$ de adição de escória. Este comportamento, segundo Kazmierczak (2007), pode estar relacionado à composição químico-mineralógica do resíduo, fato este que contribuiu para uma maior sinterabilidade dos materiais cerâmicos. Cabe salientar que em materiais cerâmicos, em temperaturas acima de $900{ }^{\circ} \mathrm{C}$ ocorre a densificação, uma consequência da vitrificação, fenômeno que ocorre na sinterização, através da formação da fase vítrea e a reação desta com fundentes presentes na massa cerâmica (ARANTES et al, 2001). Desta forma, o aumento da resistência mecânica na flexão apresentado de $850^{\circ} \mathrm{C}$ para $950^{\circ} \mathrm{C}$ das composições contendo o resíduo pode estar atribuído principalmente à contribuição do desenvolvimento das fases cristalinas, em vez da fusão e formação de fase vítrea, comportamento tipicamente refratário (VIEIRA et al, 2013; GALÁN-ARBOLEDAS et al, 2017; SERRA et al, 2014). Espera-se que esta propriedade se acentue em adições maiores de escória, na faixa de 20 a $30 \%$ como descrito por Galán-Arboledas et al (2017).
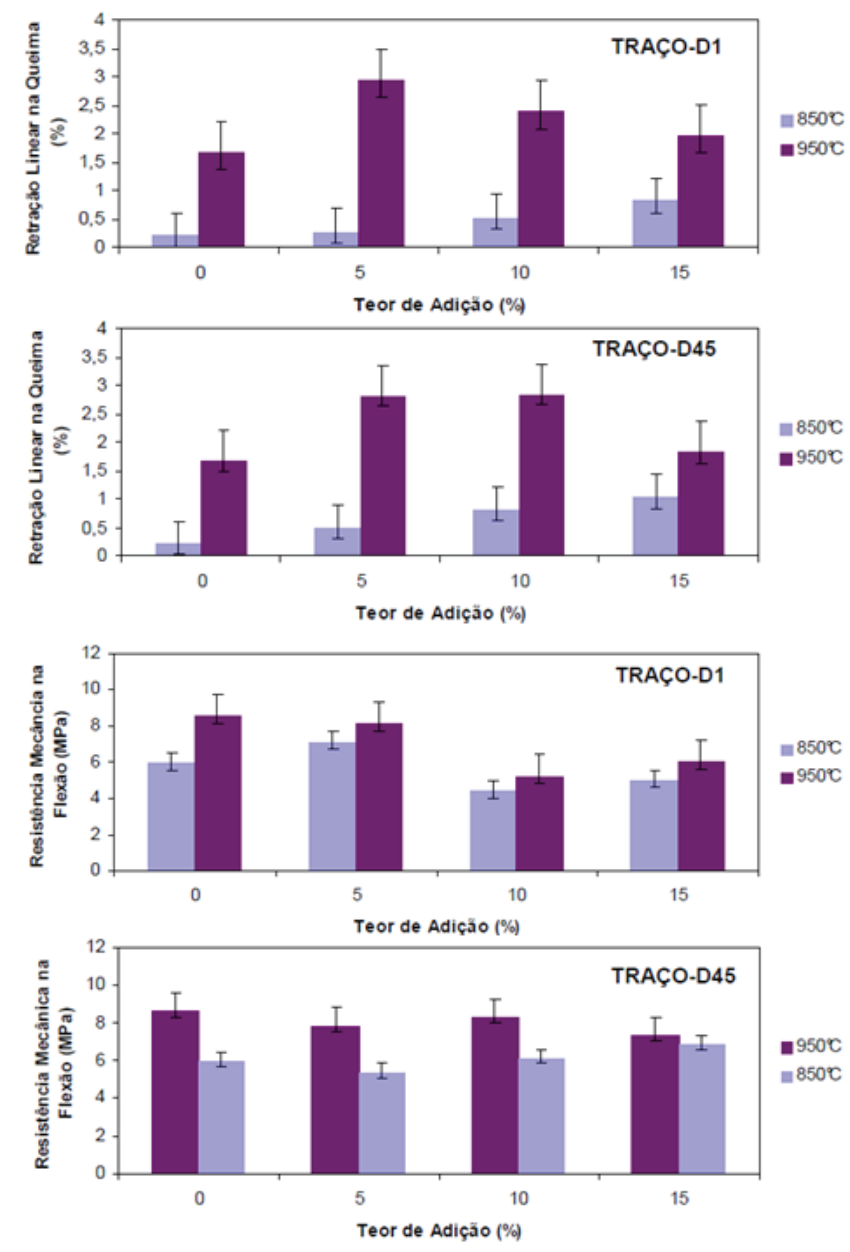

Figura 07 - Retração linear na queima e resistência mecânica na flexão Fonte: Cardoso (2009) 
Segundo a NBR 15270-1 (ABNT, 2005), o índice de absorção de água não deve ser inferior a $8 \%$ e nem superior a $22 \%$. A absorção de água variou para o traço D1, que apresentou absorções de água na faixa de 7,62 a 17,49\%, enquanto no traço D45, foram de 3,6 e 17,63 \% (Figura 8). Em relação à referência os corpos de prova D1 e D45 mantiveram valores de absorção de água similares, menos para o D1 (5 \% de adição) e D45 (10 \% de adição).
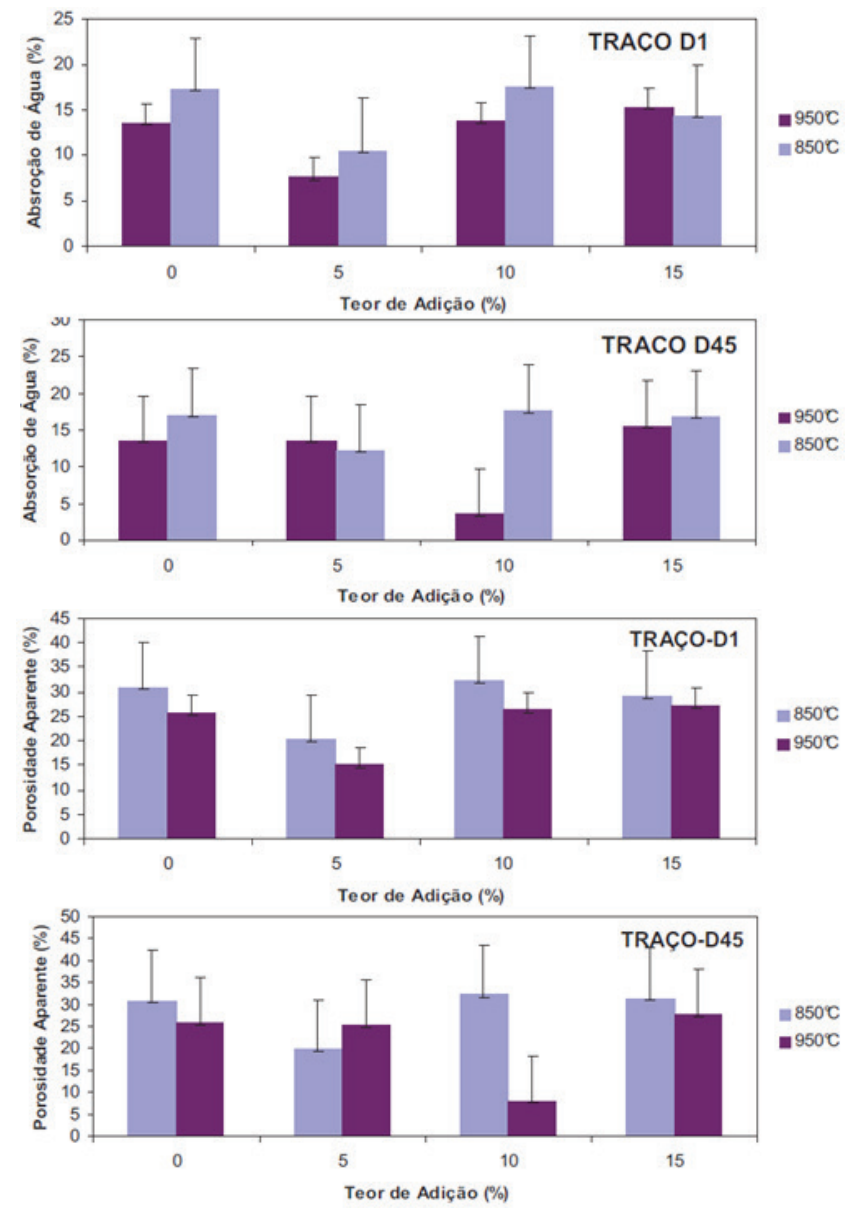

Figura 08 - Absorção de água e porosidade aparente Fonte: Cardoso (2009)

Os CP sinterizados a $950^{\circ} \mathrm{C}$ apresentaram menor absorção de água, fato provável devido a estarem mais densos, pois sua estrutura é mais compacta e menos porosa. Os CP sinterizados acima de $900{ }^{\circ} \mathrm{C}$, com adições de 5 e $10 \%$, porém com resíduo de lodo de ETE também apresentaram redução na absorção de água, de acordo com Collatto (2008), explicados devido à maior densificação do material.

Os CP D1 e D45 sinterizados na temperatura de $850^{\circ} \mathrm{C}$ ficaram dentro do especificado pela norma, enquanto os sinterizados a $950^{\circ} \mathrm{C}$, D1 com $5 \%$ e D45 com $10 \%$, ficaram fora da especificação por apresentarem uma absorção de água menor que $8 \%$. Segundo Khattab et al (2017), a resistência mecânica aumenta com o aumento da temperatura de sinterização, desta forma, uma alta resistência é obtida para as amostras sinterizadas a $950^{\circ} \mathrm{C}$, o que é atribuído à maior sinterabilidade e boa ligação interfacial entre as partículas, acompanhada de uma baixa porosidade, corroborando aos resultados obtidos neste estudo.

A porosidade aparente do traço D1 resultou na faixa de 15,08 a $32,34 \%$, enquanto para o traço D45, na faixa de 7,94 e $32,2 \%$. Para a maior temperatura, $950{ }^{\circ} \mathrm{C}$ em ambos os traços, uma menor porosidade aparente foi encontrada, exceto no teor de $5 \%$ de adição de escória no traço D45, provavelmente, devido a uma maior densificação dos CP. Quando comparados aos CP referência, os traços D1 e D45 apresentaram uma porosidade aparente similar, com exceção dos CP D1 (com 5 \%) e D45 (com 10 $\%$ ). Nos traços sinterizados a $950^{\circ} \mathrm{C}$, os $\mathrm{CP}$ apresentaram uma tendência a poros em idade aparente menor do que nos traços sinterizados a $850^{\circ} \mathrm{C}$, inclusive no CP referência. Isto possivelmente está relacionado à densificação dos $\mathrm{CP}$, exceto na temperatura de $850^{\circ} \mathrm{C}$, em ambos $\mathrm{D} 1$ e D45. À medida que o teor de escória foi aumentado, o comportamento da porosidade aparente foi acompanhado e obteve-se um aumento nesta propriedade. Nos CP sinterizados a $950^{\circ} \mathrm{C}$, a tendência de redução da porosidade aparente e absorção de água em função da adição de escória e sua vitrificação foi mascarada pelo maior aparecimento de fissuras junto a pontos brancos da amostra, correlacionados à liberação de óxidos de cálcio na superfície durante o processo de sinterização (CARDOSO, 2009).

$A$ presença de fissuras também pode estar associada à fração de areia presente na argila, por partículas com tamanho entre 0,2 e $2 \mathrm{~mm}$, que são extremamente problemáticas no estágio de queima da cerâmica pela transformação alotrópica do quartzo, que ocorre em torno de $573^{\circ} \mathrm{C}$ (VIEIRA et al, 2013). É indicado que a porosidade aparente diminua com o aumento da temperatura de sinterização, pois se deve à reação no estado sólido, ao desenvolvimento da fase e, à ação de fluxo das partículas da escória a uma temperatura mais alta. Por outro lado, a densidade aparente dos sinterizados aumenta com o aumento da temperatura de sinterização, fenômeno causado pela densificação, já discutido anteriormente (KHATTAB et al, 2017). Cabe salientar que, um aumento de porosidade representa um efeito deletério nas propriedades mecânicas (KHATTAB et al, 2012).

\subsection{Reciclagem da escória em material cerâmico}

A análise visual nos CP com escória após a secagem mostrou-se muito semelhante aos $\mathrm{CP}$ referência. Em contrapartida, essa mesma análise, nos CP analisados após a 
sinterização, apresentou uma mudança considerável na coloração com a adição do resíduo. Desta forma, as pontuações de tonalidade branca ocorreram apenas nos CP do traço D1 após a secagem e, em ambos os traços após a sinterização. Entretanto, nos CP sinterizados a $950^{\circ} \mathrm{C}$, as pontuações brancas e escuras foram mais salientes do que na temperatura de $850^{\circ} \mathrm{C}$, assim como a presença de fissuras.

A retração linear nos CP com a adição de escória D1 e D45 foi maior após a secagem do que após a queima. Os CP sinterizados correspondentes ao traço D1 com adição de 10 e 15 $\%$ de escória, apresentaram uma queda na resistência mecânica em relação à adição de $5 \%$ de escória. Enquanto nos CP referentes ao traço D45, para os mesmos teores de adição de escória, apresentaram uma melhora acentuada em relação ao traço D1. Esse aumento de resistência mecânica pode ser explicado pela densificação do material cerâmico, bem como pela presença de óxidos metálicos oriundos da escória que, de certa forma, podem ter agido como fundente no material cerâmico e, também pelo fato de uma estabilidade maior na escória D45, quando comparada à escória D1.

Buzin et al (2017) salientam que a incorporação deste tipo de resíduo em produtos cerâmicos tem recebido maior atenção pela pesquisa em razão da grande demanda por produtos dessa natureza. O baixo tamanho de partícula, desde que segregado, favorece a formação de pastas homogêneas com cimento e a mistura com argila. No entanto, aspectos importantes relacionados à composição química devem ser considerados quando este resíduo é incorporado, tanto no ambiente (cimento e blocos de construção), quanto em altas temperaturas (cerâmica). A existência de óxidos metálicos favorece a fusão e a reações químicas do resíduo com argilas, que atuam de forma desfavorável nos processos de incorporação em materiais cerâmicos a altas temperaturas, pois a presença do cromo, ou seu óxido, é devido a sua função como vitrificante, que diminui o ponto de fusão da cerâmica, ocorrendo uma fusão superficial do grão. Desta forma, deve-se avaliar a imobilização efetiva de potenciais contaminantes metálicos como o $\mathrm{Cr}$, originalmente presentes em escórias e que, neste estudo, foram encontradas quantidades traços.

\section{CONCLUSÕES}

Os resultados mecânicos mostraram que a escória tem potencialidade para ser utilizada como adição em material cerâmico, considerando as condições estabelecidas no presente trabalho.

Com a caracterização química e física da escória, comprovou-se que o beneficiamento realizado teve eficiência diferente em cada escória estudada, sendo a D1 melhor beneficiada. Isso se tornou claro mediante as análises químicas, onde houve uma maior quantidade do elemento Fe $(\approx 6 \%)$ na escória D45.

Nos corpos de prova após a sinterização à influência nas características se deve ao tipo de escória, teor de adição e temperaturas de sinterização.

Em relação ao tempo de estocagem, segundo vários estudos, não há um consenso no meio científico a respeito da estabilização volumétrica de qualquer tipo de escória. Ficou claro que a presença de contaminantes ferrosos e pontuações brancas (compostos de cálcio) na superfície dos corpos de prova cerâmicos, todos considerados compostos expansivos em escórias, demonstraram a necessidade de melhoria no processo de segregação em relação aos compostos ferrosos e, maior tempo de estabilização nas pilhas de escória para o caso dos compostos de cálcio. A partir disto, acredita-se que a estocagem utilizada neste trabalho, ainda não pode ser considerada adequada, apesar dos resultados favoráveis em termos de propriedades mecânicas. $O$ trabalho indica a necessidade de se estudar períodos de estocagem maiores, de forma a garantir a estabilização do resíduo, em especial, no que tange a presença de $\mathrm{CaO}$ livre.

\section{AGRADECIMENTOS}

A CAPES, ao Núcleo de Caracterização de Materiais (NUCMAT), ao Programa de Pós-Graduação em Engenharia Civil da Universidade do Vale do Rio dos Sinos - UNISINOS (PPGEC) e, ao CNPq pela bolsa DT2 de produtividade, que possibilitaram a realização desta pesquisa.

\section{REFERÊNCIAS}

ABNT - Associação Brasileira de Normas Técnicas. NBR 10.007: Amostragem de resíduos sólidos. Rio de Janeiro, Brasil, 2004.

ABNT - Associação Brasileira de Normas Técnicas. NBR NM 248: Agregados: determinação de composição granulométrica. Rio de Janeiro, Brasil, 2001.

ABNT - Associação Brasileira de Normas Técnicas. NBR 6508: Grãos de solos que passam na peneira de 4,8 mm: determinação da massa específica. Rio de Janeiro, Brasil, 1984.

ABNT - Associação Brasileira de Normas Técnicas. NBR 7180: Determinação do limite de plasticidade. Rio de Janeiro, Brasil, 2016.

ABNT - Associação Brasileira de Normas Técnicas. NBR 15.270-01: Componentes cerâmicos parte 1: blocos cerâmicos para alvenaria de vedação 
- terminologia e requisitos. Rio de Janeiro, Brasil, 2005.

ANICER - ASSOCIAÇÃO NACIONAL DA ONDÚSTRIA CERÂMICA. http://anicer.com.br/. Acessado em dezembro de 2017.

ARANTES, F.J.S., GALESI, D.F., QUINTEIR, E., BOSHI, A.O. O manchamento e a porosidade fechada de grês porcelanato. Cerâmica Industrial. v.6, n. 3, pp. 18-25, 2001.

ASSUNÇÃO, F.C.R., SIDERURGIA NO BRASIL 2010-2025; subsídios para tomada de decisão, 2010 Brasília: Centro de Gestão e Estudos Estratégicos, 2010. (Relatório técnico), 2010. 112 pp. http://www.cgee.org.br/atividades/ redirect.php?idProduto $=6831$. Acessado em setembro de 2020.

BUZIN, P.J.W.K.; HECK, N.C.; VILELA, A.C.F. EAF dust: An overview on the influences of physical, chemical and mineral features in its recycling and waste incorporation routes. Journal of Materials Re-search and Technology, v.6, n. 2, pp 194-202, 2017.

CASTRO, M.A.M.; DA COSTA, F.G.; BORBA, S.C.; NETO, E.F.; RABELO, A.A. Avaliação das propriedades físicas e mecânicas de blocos de solo-cimento formulados com coprodutos siderúrgicos. Revista Matéria, v. 21, n.3, pp. 666-676, 2016.

CARDOSO, M.D. Reciclagem de escória de forno panela de aciaria elétrica em material cerâmico, Dissertação (Mestrado) - Universidade do Vale do Rio dos Sinos UNISINOS, São Leopoldo, RS, Brasil, 2009.

CEMP - Comissão de Estudos de Matérias Primas. CEMP 105: Materiais para fundição: Determinação do Teor de Umidade. São Paulo, Brasil, 2003.

CEMP - Comissão de Estudos de Matérias Primas. CEMP 120: Materiais para fundição: Determinação da Perda ao Fogo. São Paulo, Brasil, 2003.

CESAR, A.C.G. Desenvolvimento de blocos confeccionados com escória proveniente da reciclagem do aço, Dissertação (Mestrado), EESC, São Carlos, SP, Brasil, 2008.

CIKMIT, A.A., TSUCHIDA, T., HASHIMOTO, R., HONDA, H., KANG, G.; SOGAWA, K. Expansion characteristic of steel slag mixed with soft clay. Construction and Building Materials, 227, 116799, 2019.

COLLATTO, D. Utilização de resíduo proveniente da estação de tratamento de efluentes de indústria de papel como matéria-prima na fabricação de cerâmica vermelha. Dissertação de M. Sc., UFRGS, Porto Alegre, 2008.

COSTA, K.A.; GUIMARÃES, A.C.R.; REIS, M.M.; SANTANA,
C.S.A. Estudo do processo de lixiviação controlada da escória de aciaria em extrator soxhlet visando empregos em pavimentos. Revista Matéria, v. 22, n.2, 2017. DOS SANTOS, E.; QUEIROZ, A.P.; Seu tijolo está manchando? Conheça a influência do cimento sobre a formação da eflorescência. Cerâmica Industrial, v. 21, n.3, Maio/Junho, 2016.

DO PADRO, U.S; BRESSIANI, J.C. Panorama da indústria cerâmica brasileira na última década. Cerâmica Industrial, v. 18, n. 1, pp. 7-11, Jan/fev, 2013.

FISHER, L.V.; BARRON, A.R. The recycling and reuse of steelmaking slag - A review. Resources, Conservation \& Recycling, v.146, pp 244-255, 2019.

GALÁN-ARBOLEDAS, R.J.; DIEGO, J.A.; DONDI, M.; BUENO, S. Energy, environmental and technical assessment for the incorporation of EAF stainless steel slag in ceramic building materials. Journal of Cleaner Production. v.142, pp 1778-1788, 2017.

GEYER, R. M. T. Estudo sobre a potencialidade de uso das escórias de aciaria como adição ao concreto. Tese (Doutorado) UFRGS, Porto Alegre, 2001.

GRAFFITTI, D.F. Avaliação do Teor de Cal Livre em Escória da Aciaria Elétrica. Dissertação de M. Sc., UFGRS, Porto Alegre, 2002.

GRAFFITTI, D.F; ALVES, C.R.R.; VILELA, A.C.F.; MORAES, C.A.M. Determinação de cal livre em escória de aciaria elétrica como contribuição para avaliação de sua expansibilidade, Tecnologia em Metalurgia e Materiais, v. 2, n. 2, pp. 24-28, out/dez, 2005.

GUMIERI, A.G. Estudo da viabilidade técnica da utilização de escória de aciaria do processo LD como adição em cimentos. Tese (Doutorado). UFRGS, Porto Alegre, 2002.

HU, P., PAN, D., WANG, X., TIAN, J., WANG, J., ZHANG, S., VOLINSKY, A. Fuel additives and heat treatment effects on nanocrystalline zinc ferrite phase composition. Journal Magnetism and Magnetism Materials, v. 323, pp 569-573, 2011.

INSTITUTO AÇO BRASIL. Relatório de Sustentabilidade 2018. Disponível em: http://www.acobrasil.org.br/sustentabilidade/assets/pdfs/Aco-Brasil-Completo.pdf Acesso em setembro de 2020.

KAZMIERCZAK, C. S. Produtos de cerâmica vermelha: materiais da construção civil e princípios de ciência e engenharia de materiais, São Paulo, v.1, pp. 563-585, 2007.

KHATTAB, R.M., WAHSH, M.S.M.; KHALIL, N.M. Preparation and characterization of porous alumina ceramics through starch consolidation casting 
technique. Ceramics International. v. 38, n. 6, pp 4723-4728, 2012.

KHATTAB, R.M., EL-SAYED SELEMAN, M.M., ZAWRAH, M.F. Assessment of electric arc furnace dust: Powder characterization and its sinterability as ceramic product. Ceramics International, v. 43, pp 12939-12947, 2017.

MARCACCINI, G. C. S. Estudo experimental de laboratório para emprego da escória de aciaria como agregado em camadas de base de pavimento flexível. Trabalho de Conclusão de Curso de Engenharia Civil da UFSC, Florianópolis, 2009.

MORAES, C.A.M.; CALHEIRO, D.; VARGAS, M.; SANTOS, C.; NETO, F.A.O.; PIRES, D.C. Avaliação da minimização com consumo de cal em aciaria elétrica e sua contribuição para a redução de emissão de gases de efeito estufa. In: XL Seminário de Aciaria Internacional, pp. 443- 453, 2009.

NISHIGAKI, M. Producing permeable blocks and pavement bricks from molten slag. Waste Management. v. 20, pp. 185-192, 2000.

PASCHOAL, J. A. A. Estudo de parâmetros de qualidade para a cerâmica estrutural vermelha. Dissertação (Mestrado) UFSCAR, São Carlos, 2003.

PICKLES, C.A. Thermodynamic analysis of the selective chlorination of electric arc furnace dust. Journal of Hazardous Materials, v.166, n.2-3, pp 1030-1042, 2008.

RÊGO, V.R. Efeito da adição da escória de aciaria em formulações de massa cerâmica para telhas. Tese (Doutorado) UFRN, Natal, RN, Brasil, 2010.

REHÁCKOVÁ, L.; ROSYPALOVÁ, S.; DUDEK, R.; KUKUTSCHOVÁ, J. Effect of $\mathrm{CaO} / \mathrm{SiO} 2$ ratio on viscosity and structure of slag. Metalurgija, v.54, n.3, pp 455458, 2015.

RIZZO, E.M.S.; Introdução aos processos de refino secundário dos aços. $A B M, p p . ~ 102,2006$.

RONDA FILHO, W. M. M. Levantamento de resíduos sólidos gerados no refino primário (aciaria LD) de ferro gusa. Monografia Engenharia Metalúrgica, UFRJ, Rio de Janeiro, 2016.

SERRA, M.F.; ACEBEDO, M.F.; CONCONI, M.S.; SUAREZ, G.; AGLIETTI, E.F.; RENDTORFF, N.M. Thermal evolution of the mechanical properties of calcareous earthenware. Ceramics International. v.40, pp 1709-1716, 2014. SILVA, C. N. P. Um estudo sobre a viabilidade da utilização de escória de aciaria LD em camadas de pavimentos. Dissertação (Mestrado) Instituto Militar de Engenharia, Rio de Janeiro, 2013.
SORLINI, S. SANZE NI, A., RONDI, L. Reuse of steel slag in bituminous paving mixtures. Journal of Hazardous Materials. v. 209- 210, pp. 84- 91, 2012.

STATHOPOULO, V.N., PAPANDREOU, A., KANELLOPOULOU, D., STOURNARAS, C.J. Structural ceramics containing electric arc furnace dust. Journal of Hazardous Materials, v. 262, pp. 91-99, 2013.

VIANA, C.E.; DIAS, D.P.; PARANHOS, R.P.R.; HOLANDA, J.N.F. Influência da incorporação de resíduo de escória de fluxo de soldagem nas propriedades tecnológicas de argamassa de múltiplo uso e cerâmica vermelha para construção civil. Cerâmica, v. 56, pp. 83-90, 2010. VIEIRA, C.M.F.; SANCHEZ, R.; MONTEIRO, S.N.; LALLA, N.; QUARANTA, N. Recycling of electric arc furnace dust into red ceramic. Journal of Materials Research and Technology, v.2, n.2, pp 88-92, 2013.

WANNAKAMB, S., MANUSKIJSAMRUN, S., BUGGAKUPTA, W. The use of electric arc furnace dust from steel recycling in ceramic glaze, Suranaree. Journal Science and Technology, v. 20, n. 4, pp 329337, 2013.

ZETTERMANN, L. F. Caracterização da escória de aço inoxidável com vistas a seu reaproveitamento no processo de produção do aço. Dissertação de M. Sc., UFRGS, Porto Alegre, 2001. 


\section{AUTORES}

ORCID: 0000-0001-5533-2537

MARílIA DUARTE CARDOSO, M.Sc. | Unisinos | Programa de Pós Graduação em Engenharia Civil | São Leopoldo, RIO GRANDE DO SUL(RS) - Brasil | Correspondência para: Av. Unisinos, 950 - Cristo Rei, São Leopoldo - RS, 93022-750) | E-mail: marilia.geologia@gmail.com

ORCID: 0000-0002-7164-6656

ALINI LUISA DIEHL CAMACHO, M.Sc. | Unisinos | Programa de Pós Graduação em Engenharia Civil | São Leopoldo, RIO GRANDE DO SUL(RS) - Brasil | Correspondência para: Av. Unisinos, 950 - Cristo Rei, São Leopoldo - RS, 93022-750) | E-mail: alinidiehl@gmail.com

ORCID: 0000-0001-7295-2826

CARLOS ALBERTO MENDES MORAES, Dr. | Unisinos | Programas de Pós Graduação em Engenharia Civil - PPGEC, e em Engenharia Mecânica - PPGEM | São Leopoldo, RIO GRANDE DO SUL(RS) - Brasil | Correspondência para: Av. Unisinos, 950 - Cristo Rei, São Leopoldo - RS, 93022-750) | E-mail: cmoraes@unisinos.br

\section{COMO CITAR ESTE ARTIGO}

CARDOSO, Marília Duarte; CAMACHO, Alini Luísa Diehl; MORAES, Carlos Alberto Mendes. Avaliação Mecânica E Estrutural Da Adição De Escória Do Refino Secundário Via Aciaria Elétrica Em Material Cerâmico Em Função Do Tempo De Estocagem Do Resíduo. MIX Sustentável, [S.I.], v. 7, n. 1, p. 111-124, dez. 2020. ISSN 24473073. Disponível em:<http://www.nexos. ufsc.br/index.php/mixsustentavel>. Acesso em: dia mês. ano. doi:https://doi.org/10.29183/2447-3073. MIX2020.v7.n1.111-124.

DATA DE ENVI0: 30/07/2020

DATA DE ACEITE: 29/09/2020 